\title{
RESEARCH REGARDING THE DESIGN OF A CLOSED-LOOP PNEUMATIC POSITIONING SYSTEM WITHOUT USING PROPORTIONAL EQUIPMENT
}

\author{
Avram Mihai ${ }^{1}$, Constantin Victor ${ }^{2}$, Amza Meral $^{3}$ \\ Mechatronics and Precision Mechanics Department, University Politehnica of Bucharest \\ Spl. Independentei 313, Bucharest, Romania \\ mavram02@yahoo.com, victor.f.constantin@gmail.com, meral.amza@gmail.com
}

\begin{abstract}
The paper shows the design, manufacturing and testing of a new type of closed-loop pneumatic positioning system. The design is comprised solely of on/off equipment, which ensures overall low cost. Exhaust flow control and thus speed control for both directions of movement is done by means of several groups of way valves. This ensures that the system can obtain different speeds. Maximum speed is obtained when all of the way valves are open and minimum speed is obtained by using only one way valve. The last version is used close to the desired position to ensure the low speed needed to obtain precision. System control is done by means of a microcontroller that stores and executes the working programs.
\end{abstract}

Keywords: Pneumatic, Positioning, Microcontroller, Mechatronics.

\section{Introduction}

Many industrial applications require a precised positioning of a load handled by a pneumatic cylinder in certain points of its working stroke [1]. This is the reason why manufacturing companies provides users with pneumatic positioning systems. Unfortunatelly, only a tenth of a millimiter positioning accuracy can be achieved due to the high compressibility and low viscosity of the environment [2], [3], [4]. Increased positioning accuracy and, especially, preservation position over time remain difficult tasks to solve, requiring extensive theoretical and applied research. [5]

Prestigious companies in the field try to promote such systems. FESTO, for example, produces both the equipment needed for the development of pneumatic positioning systems as well as the modular structures of such systems. Industrial systems are controlled via the SPC200 controller [6].

These units are structured around proportional pneumatic equipments, which are expensive. The price of the equipment refflects on the price of the whole unit. The basic equipment from the structure of a pneumatic positioning system are proportional valves. For this reason, currently, these units used only sometimes. Sustainable efforts are made in this direction in order to reduce the costs.[7]

An example of a solution that attempts to solve this problem is proposed by SMC (fig.1, [8], [9]).
The positioning system created by this company uses only classical equipment to position a load and manages to obtain a position with an error of $\pm 0.1 \mathrm{~mm}$.

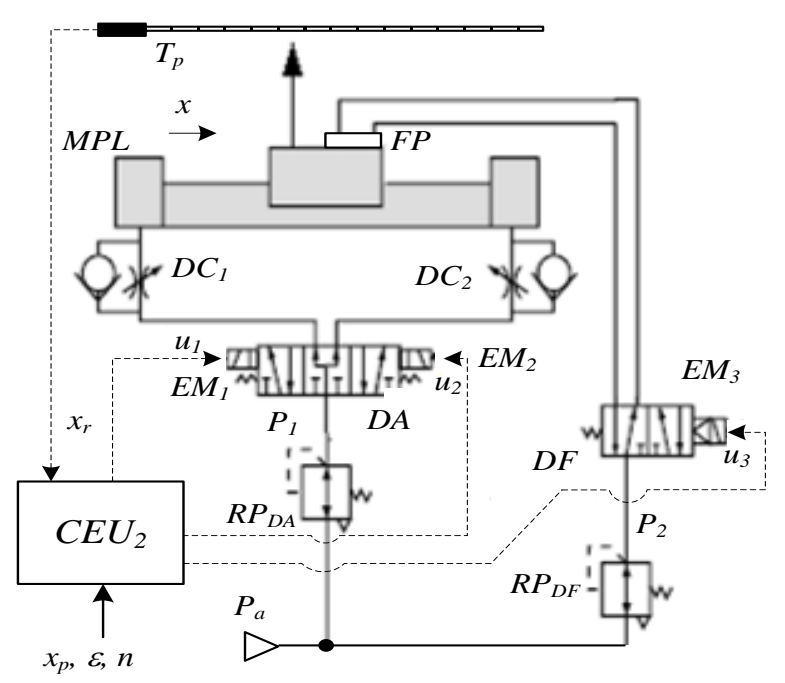

Fig. 1. Scheme of the solution of SMC

This positioning system uses only equipment driven by a CEU2 controller designed specifically for such applications. In its memory is implemented an algorithm designed for such applications.

The following classical equipments can be identified in the structure of the system: a special linear pneumatic motor, MPL, with a incremental position transducer, $\mathrm{Tp}$, and a braking system integrated in its construction, SF, a valve, DA, a brake 
valve, DF, two pressure regulators, RPDA and RPDF, and one-way flow control valves, DC1 and DC2.

The mobile unit of the actuator and the trained load, implicitly, are blocked because the three voltages $\mathrm{u} 1, \mathrm{u} 2$ and $\mathrm{u} 3$ are zero in the positions programmed because. In this case, the active chambers of equal section of the cylinder are fed with the same pressure P1 (the DA supply valve switches to the preferential position), and the pneumatic brake, FP is switched-on (the DF brake valve activates this brake in the preferential position).

Supposing that the mobile assembly is stationary in point $\mathrm{x} 0$, movement will be possible when the DF valve is actuated, meaning that voltage $\mathrm{u} 3$ is supplied.

For example, the movement to the right (eg fig. 2) will be possible when the control voltage $u 1$ is supplied. The command of the valve DA stops at a certain distance from the target position xfi and movement continues due to inertia.

The DF valve will lock the brake when the positioning sensor, Tp, indicates the $\mathrm{xp}-\varepsilon$ value. It is possible that the actual switching off of the moving unit to be made with an error greater than the one imposed at XSTOP, i.

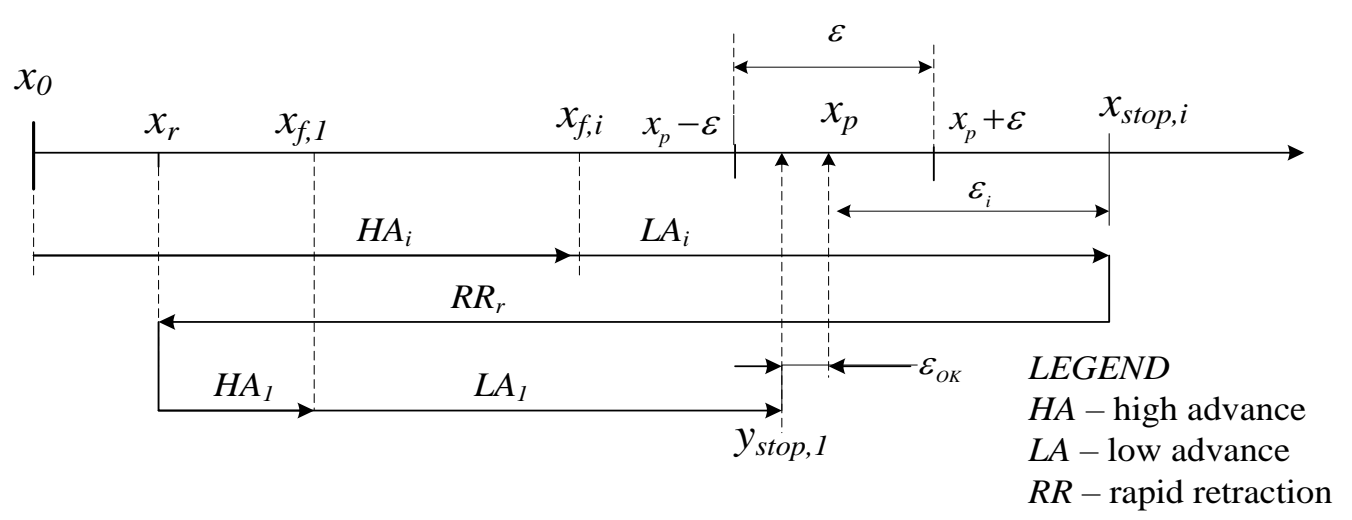

Fig. 2. Working principle of the SMC positioning system

If the positioning is not succesful after the first try, the unit returns to a preset point $\mathrm{xr}$ and a new positioning is attempted, this time from a different point, corrected with the error obtained for the initial test. The cycle repeats until an error of $\pm 0.1 \mathrm{~mm}$ is obtained.

In the paper [10] the authors present two similar variants of pneumatic positioning systems without proportional equipments that differ in therms of command. The hardware structure of the pneumatic system is made with classical equipment manufactured by SMC, as in the example already presented.

The first solution uses a data acquisition board and a PC to command the system. The working program was performed in LabVIEW programming environment. Adding a PC to the system allows easy user intervention on the system's control parameters during its operation but significantly increases the cost of the system.

A control system with a PIC microcontroller was selected for the second solution. The decisionmaking part of this variation depends entirely on the program written in the controller's memory; ; it is not possible to interfere with the positioning algorithm during system operation.

The two variants developed in this paper have been experimentally tested. The tests showed that the positioning accuracy of $\pm 0.1 \mathrm{~mm}$ is possible in both cases. The second solution is preferred in terms of costs. The electronic components used are available today, they are produced in series and can be purchased at very low prices.

\section{The Proposed Solution}

Several verisons were analyzed for the functional scheme by using the FluidSim software, which also allows verification of their functionality. Finally, the optimal option was chosen. It is shown in figure 3 and has in its structure the following component equipment:

- MPL, linear pneumatic cylinder of special construction, rodless, with magnetic coupling;

- $\mathrm{T}_{\mathrm{p}}$, incremental position transducer;

- $S_{1}, S_{2}$, shut-off valves, pneumatically releasable;

- $\mathrm{DP}_{1}, \mathrm{DP}_{2}, 3 / 2$ way solenoid pneumatic valves, with preferential position;

- $\mathrm{DP}_{3} 3 / 2$ way solenoid pneumatic valve, for valve release control;

- $\mathrm{BD}_{1}$, valve terminals that consist of $2 / 2$ way valves, $\mathrm{D}_{11}, \mathrm{D}_{12}, \mathrm{D}_{13}$ and $\mathrm{D}_{14}$;

- $\mathrm{BD}_{2}$, valve terminals that consist of $2 / 2$ way valves, $\mathrm{D}_{21}, \mathrm{D}_{22}, \mathrm{D}_{23}$ and $\mathrm{D}_{24}$;

- Dr1, Dr2, flow control valves; 


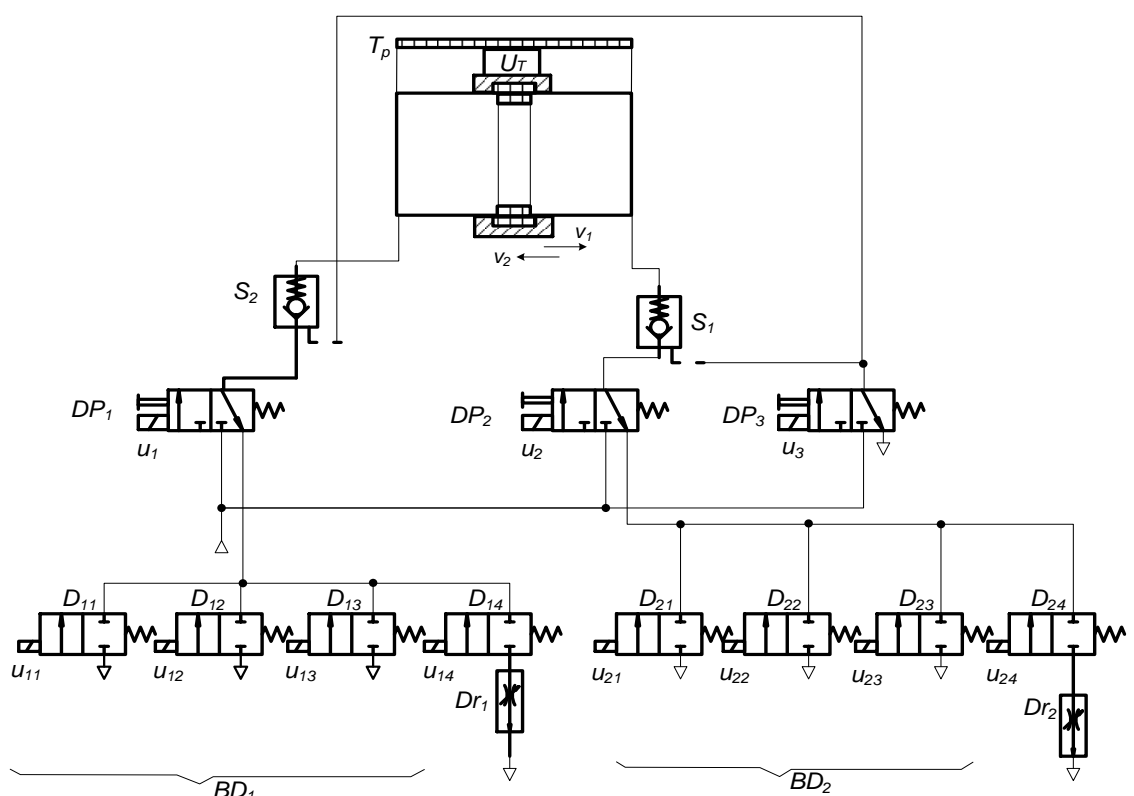

Fig. 3. Schematics of the proposed solution

Two microcontrollers ATmega328, $\mu \mathrm{C}_{1}$ and $\mu \mathrm{C}_{2}$, were chosen for the control system [11]. The first microcontroller, $\mu \mathrm{C}_{1}$, mounted on an Arduino development board [12], receives information from the position transducer, $\mathrm{T}_{\mathrm{p}}$, and transmits it in realtime via wireless to the microcontroller $\mu \mathrm{C}_{2}$. This structure forms the transmitter unit (Figure 4), a unit located on the moving table of the cylinder.

The second microcontroller, $\mu \mathrm{C}_{2}$, is part of the receiver electronic unit (Figure 5) an dis located on the motherboard of the entire system. This microcontroller receives the signals transmitted by the first block and generates control signals for the electromagnets of the system as the algortihm from thememory of the microcontroller requires or not in a certain stage of the working cycle. To be useful, these signals, once generated by the microcontroller, must be amplified. This module has this function too.

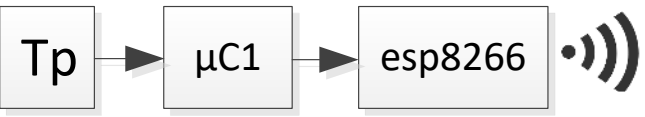

Fig. 4. Transmitter unit

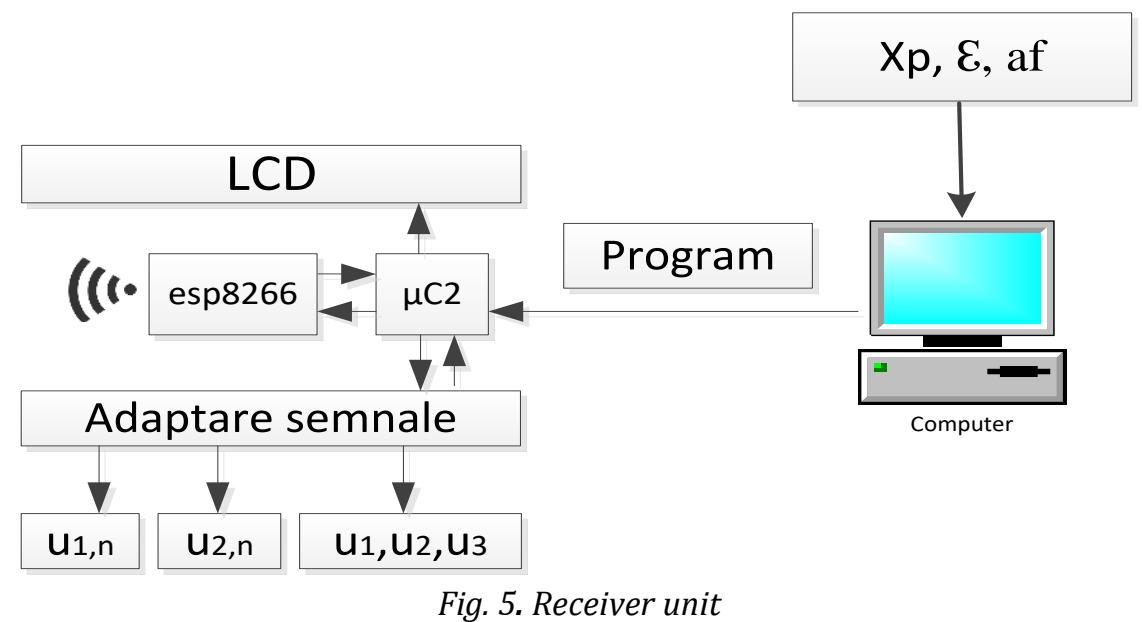

In order to visualize the obtained position, a digital display module was added to the system.

In stationary positions, all digital signals controlled by the receiver electronics unit have a logical value of zero. In this situation, the two active chambers of the linear pneumatic cylinder are locked by the two valves S1 and S2.
Movement is possible after supplying the $u 3$ signal that will unlock the two valves. The movement to the right in the direction of speed $\mathrm{v} 1$ is possible when the $\mathrm{u} 1$ signal is supplied. The stabilized value of speed depends on how the command signals for the BD2 terminal are supplied. This is highlighted in Table 1 and Figure 6. 


\begin{tabular}{|l|l|l|l|l|l|}
\cline { 2 - 7 } \multicolumn{1}{c|}{} & $u_{21}$ & $u_{22}$ & $u_{23}$ & $u_{24}$ & $v_{1 r}$ \\
\hline I & 1 & 1 & 1 & 1 & $v_{1 r, \max }$ \\
\hline II & 0 & 1 & 1 & 1 & $v_{f, 11}$ \\
\hline III & 0 & 0 & 1 & 1 & $v_{f, 12}$ \\
\hline IV & 0 & 0 & 0 & 1 & $v_{f, 13}$ \\
\hline
\end{tabular}

Table 2. Steps of speed obtained with BD1

\begin{tabular}{|l|l|l|l|l|l|}
\cline { 2 - 6 } \multicolumn{1}{c|}{} & $\mathrm{U}_{11}$ & $U_{12}$ & $U_{13}$ & $U_{14}$ & $v_{2 r}$ \\
\hline I & 1 & 1 & 1 & 1 & $v_{2 r, m a x}$ \\
\hline II & 0 & 1 & 1 & 1 & $v_{f, 21}$ \\
\hline III & 0 & 0 & 1 & 1 & $v_{f, 22}$ \\
\hline IV & 0 & 0 & 0 & 1 & $v_{f, 23}$ \\
\hline
\end{tabular}

Note:

In the tables above "1" is the logical value that corresponds to the situation where the supply voltage is a $24 \mathrm{~V}$, and " 0 " is the logical value to the situation in which this voltage is $0 \mathrm{~V}$.

The displacement to the right, in the direction of speed v2 is possible when the u2 signal is supplied. The stabilized value of speed depends on how the control signals for the BD1 terminal valve are supplied. This is highlighted in Table 2.

The precise positioning of the driven working load is helped by the reduction of the mobile unit speed near the desired stopping point. As already shown, by supplying control signals to the electromagnets of the two terminal valves, three different values for the braking rate can be obtained.

The desired values for the three braking speeds $\mathrm{Vff}_{11}, \mathrm{Vf}_{12}, \mathrm{Vf}_{13}$ or $\mathrm{Vf}_{\mathrm{f}, 21}, \mathrm{Vf}_{\mathrm{f}, 22}, \mathrm{Vf}, 23$ can be obtained by a manual adjustment of the $\operatorname{Dr}_{1}$ or $\operatorname{Dr}_{2}$ flow section.

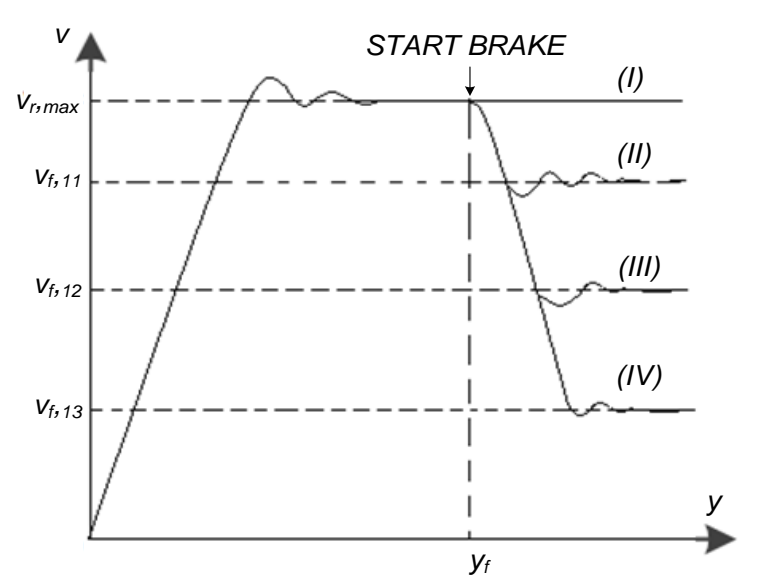

Fig. 6. Regulation of speed after starting brake

\section{The Experimental Model}

For the design of the experimental model the following values were imposed: the effective force developed by the cylinder $\mathrm{Fu}=400 \mathrm{~N}$, the working stroke $\mathrm{c}=600 \mathrm{~mm}$ and the supply pressure $\mathrm{pa}=6$ bar.

For these values, the dimensioning calculations [13], [14], [15] were performed and the necessary automation pneumatic equipment were selected from the catalogues of the producing companies [16], as follows:

- linear pneumatic cylinder, rodless, with magnetic coupling: RMS -_- $32 \times 600$-- $\mathrm{P}$, manufactured by AIRTAC;

- valve terminals, MZH-3-0,4-K, produced by Festo;

- 3/2 way solenoid pneumatic valves: 4V11006, manufactured by AIRTAC;

- shut-off valves- HGL-1/2-B, produced by Festo;

- flow control valve: GRGO-M3-QS-3, produced by Festo.

The next step consisted in designing the mechanical part of the meel using SolidWorks. Figure 7 shows the actuator subassembly comprising the linear pneumatic cylinder 1 , the mounting plate 2 , two end supports 3 , two guide rods 4 and the supporting table 5 .

The guide table in relation to the two guide rods is provided by means of four linear bearings (not shown) mounted pressed into the table. In this way the trained load (fixed on the mobile table) will be secured against rotation. 


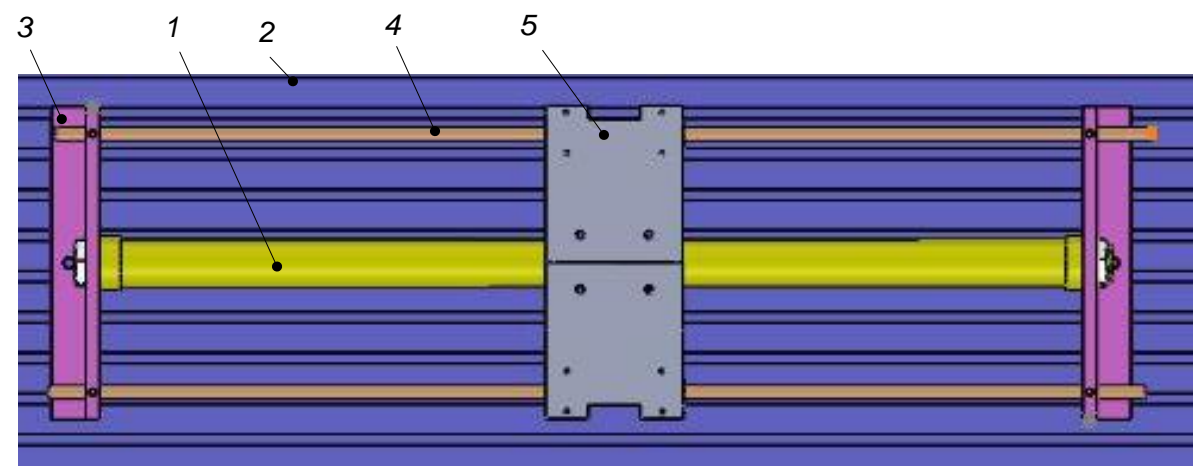

Fig. 7. SolidWorks projected assembly

The position transducer, a linear magnetic one, is AS5304 and belongs to AMS. Its sensitive element was mounted on an adapter plate (fig. 8), to which the connecting pins were then connected, whit the help of which the connection between the transducer and the microcontroller ${ }^{2} \mathrm{C}_{1}$ is realized.

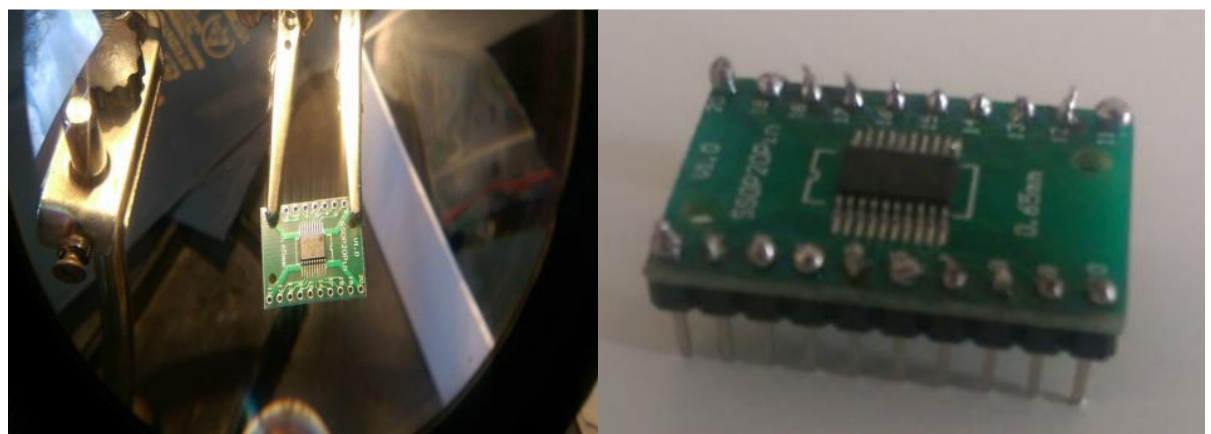

Fig. 8. Position transducer AS5304

The transducer [17] is an integrated circuit made up of a sensitive element with integrated Hall elements to measure linear motion using the multipole magnetic strip. Applications with transducers of this type require the transducer's sensitive element to be mounted over the magnetic strip at a small distance. The transducer can retrieve information at high speeds of up to $20 \mathrm{~m} / \mathrm{s}$, has a resolution of $25 \mu \mathrm{m}$, two incremental quadrature outputs and operates at a voltage between 4.5-5.5V.

To test the functionality of the transducer and the correctness of the circuit, a simple assembly was designed and made (fig.9). With the integrated oscilloscope in this assembly, the output signals provided by the transducer can be tracked.

The ESP8266 wireless module (fig.10) is used to transmit the data between the two electronic units (the tranmsitter, which is mobile, and the receiver, which is fixed). This is an integrated WiFi circuit that can communicate with other devices like Arduino via UART serial protocol at a high frequency. It has a non-volatile memory of $1 \mathrm{MB}$ and has two pins in its structure that can be used similarly to the digital pins on the Arduino plaque.

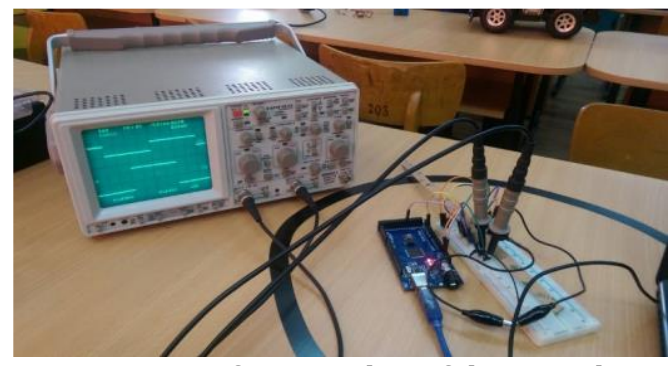

Fig. 9. Testing functionality of the transducer

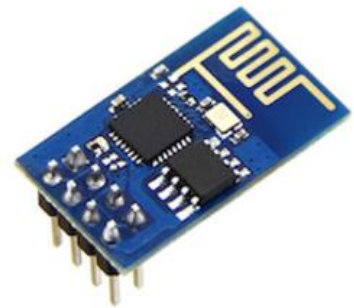

Fig. 10. Wi-fi module, ESP8266

Figure 11 shows the two electronic units connected together. 


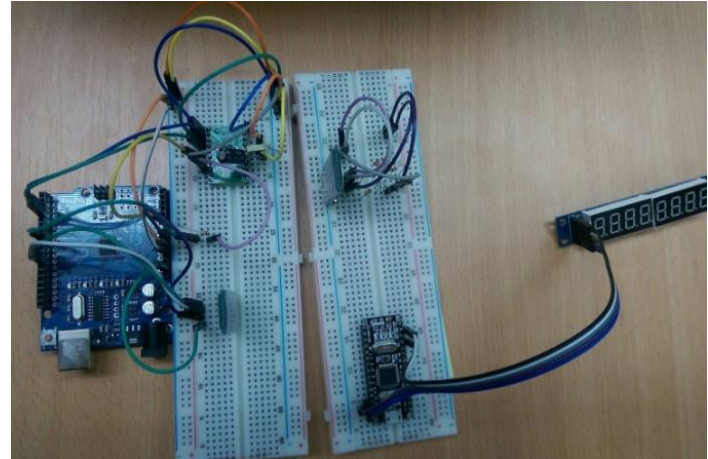

Fig. 11. Transmitter and receiver unit

\section{The Control Algorithms}

To obtain a precise positioning, the control algorithm from Figure 12 was designed. Afterwards, based on this algorithm, the working program of the system will be performed, which will then be transferred to the memory of the microcontroller.

The algorithm involves achieving multi-stage positioning. First of all, the following must be specified: the point where you want to achieve the positioning - yp, the admitted error, $\varepsilon$, and the distance from the target - from which braking must begin.

The initial stage involves searching for the reference position, which will be facilitated by the existence of two proximity sensors mounted at the cylinder's travel ends. The reference position will be chosen according to the direction in which the mobile assembly is to be moved. The load, in the reference position, starts moving at maximum speed to point yp-af. From this moment, the movment of the mobile assembly continues, in a first step with the speed vf,11 (Table 1 - line 2 and figure 6 - II).

If the positioning with the imposed error fails in these conditions, the mobile assembly returns to position yp - af at a speed vf,23 (Table 2 - line 4). From this moment the displacement continues to the target position yp with a lower speed, vf,12 (Table 1 - line 3 and Figure 6 - III). If the positioning fails any time again, a new Vf, 123 ) is performed. (Table 1 Line 4 and Figure 6 - IV).

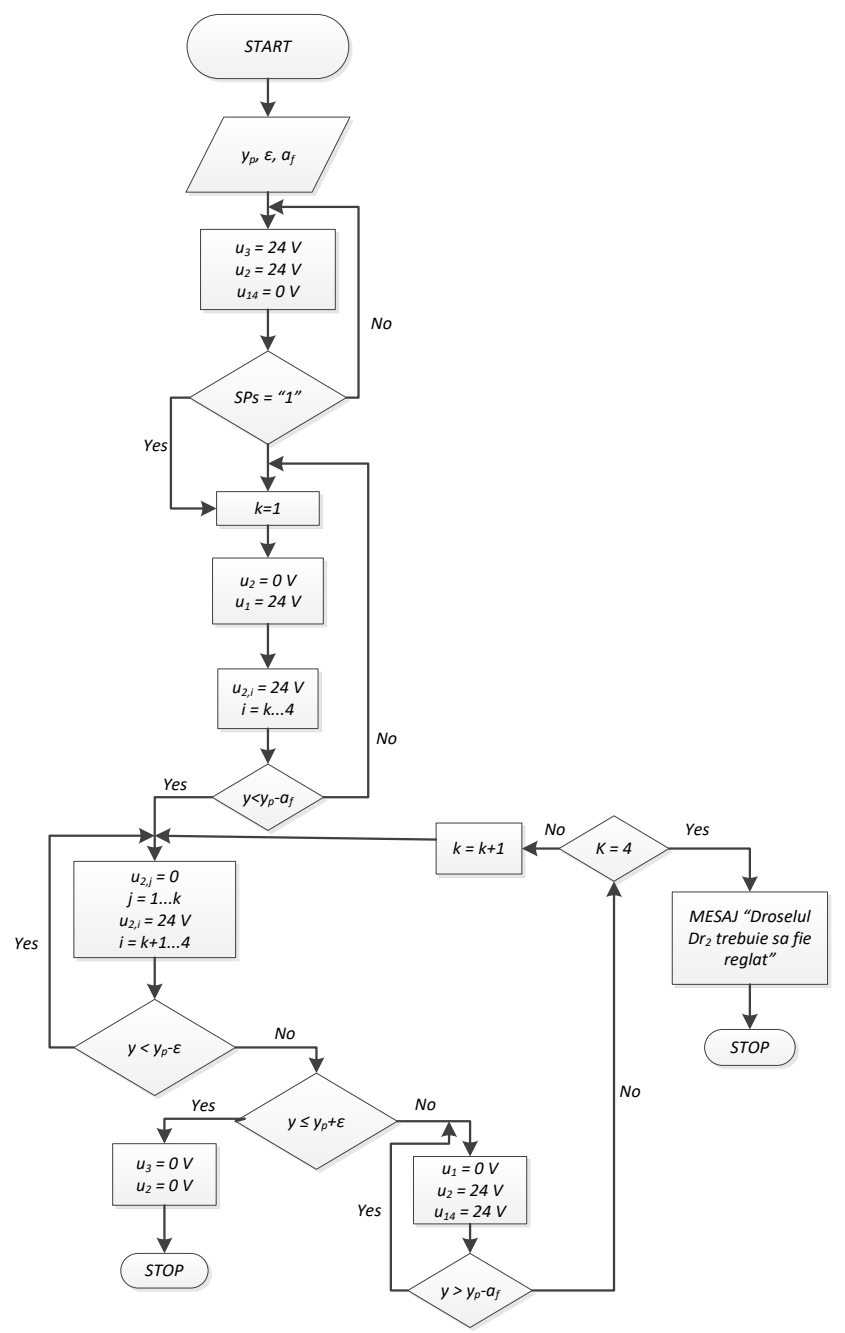

Fig. 12. Logic scheme of the control algorithm 
If the positioning with the required error can not be made, the algorithm warns the user and recommends the manual modification of the flowing section of Dr1 (fig.3).

Then the algorithm resumes and the operation continues until a load positioning with the required error is obtained.

\section{Conclusions}

The paper aims to present an original positioning pneumatic system in terms of both hardware structure and software. The proposed solution is a cost-effective alternative to the existing positioning systems with proportional equipment. The elaborated algorithm allows positioning of the trained load at any point on the stroke with an imposed error. The absence of proportional equipment has been successfully compensated by the control electronics and the positioning algorithm.

The present study will be continued, the next steps include obtaining the experimental model, testing and optimizing it in terms of construction and functionality.

Considering the current context and trends in the industrial field, which involves continuously automatization. With this being said, there is a need of reliable alternatives. This paper is part of the efforts made in this direction.

In conclusion, this paper is an example of a mechatronic system that combines elements related to the three domains, in order to present a flexible unit with a high degree of applicability.

\section{References}

[1] Freundt, M., Brecher, C., Wenzel, C., Pyschny, N.: Pneumatic positioning system for precision assembly, Acchen, Germany, IFIP - International Federation for Information Processing book series, ISBN 978-0-387-77405-3 (2008).

[2] Edmond, R., Yildirim, H.: A High Performance Pneumatic Force Actuator System, Part 1 Nonlinear Mathematical Model", Journal of Dynamic Systems Measurment and Control 122(3), DOI: 10.1115/1.2=1286366 September (2000).

[3] Nurtaç Akdag, F., Kuzucu, A.: Highly accurate pneumatic position control, Istanbul, http://digital.ni.com/;
[4] Lai, W.K., Rahmat, M.F., Abdul Wahab, N.: Modeling and controller design of pneumatic actuator system with control valve", Skudai, Malaysia, International Journal on Smart Sensing and Intelligent Systems, 5 (3). pp. 624-644. ISSN 1178-5608 (2012).

[5] Frederic, A., Xavier, B., Sesmat S., Bideaux, E.: Non-linear position control of a pneumatic actuator with closed-loop stiffness and damping tuning, Zurch, Switzerland, Control Conference (ECC), IEEE, 13936228 (2013).

[6] http://festo.com/.

[7] Thomas, M. B., Maul, G. P., Jayawiyanto, E.: A novel, Low-cost Pneumatic Positioning System, Ohio, USA, Journal of Manufacturing Systems, Volume 24, Issue 4, pages 377-387, (2005).

[8] http://www.smcusa.com/products/CEU2Controller-for-CE2-Series 20617

[9] Avram, M., Bucșan C.: Sisteme de acționare pneumatice inteligent, Editura Politehnica PRESS, Bucuresti (2014).

[10] Avram, M., Constantin, V.: Controlling of a pneutronic positioning system without proportional equipment, Romanian Review Precision Mechanics, Optics and Mechatronics No. 39, pp. 82-85, ISSN 1584-5982, (2011).

[11] Matousek, P.: Microprocessor system designated for control pneumatic actuator, Liberec, Czech Republic, Journal of applied sciens in the thermodynamics and fluid mechanics, Vol. 5, No. 2/2011, ISSN 1802 - 9388, (2011).

[12] https://www.arduino.cc/.

[13] Avram, M. :Acționări hidraulice și pneumatic, Ed a 3-a, rev. - București: Editura Universitară, Bibliogr. ISBN 973-7787-40-4 (2005).

[14] Dr. Dihovicni, D., Dr. Medenica, M. :Mathematical Modelling and Simulation of Pneumatic Systems, Serbia, Advances in Computer Science and Engineering, book edited by Schimdt, M., ISBN 972-953-307-173-2, Published: March 22 (2011).

Blagojevic, V., Stojiljkovic, M.: Mathematical and Simulink Model of the pneumatic system with bridging of the dual cylinder chambers, Republic of Serbia, Facta universitatis-series: Mechanical Engineering, 5(1): p. 23-31 (2007).

[15] http://airo-pneumatics.ro.

[16] http://ams.com - AS5304-06_Datasheet_EN_v2 .

[17] Guenther, R., Perondi, E. C., DePieri, E.R., Valderio, A. C.: Cascade Controlled Positiong System with LuGre Model Based Friction Compensation, Braz, J., Soc. Mech. Sci. \& Eng. [online]., vol.28, n.1, pp.48-57. ISSN 1678-5878. http://dx.doi.org/10.1590/S1678$\underline{58782006000100006}$ (2006). 